\title{
تغيرات فئات الرطوية النسبية في العراق
}

\author{
أ.م.د بشرى أحمد جواد صالح \\ الجامعة المستتصرية/ كلية التربية
}

الملخص:

يرمي هذا البحث دراسة التغيرات في فئات الرطوبة النسبية التي تم تقسيمها على وفق تصنيف العالم رافنشتين

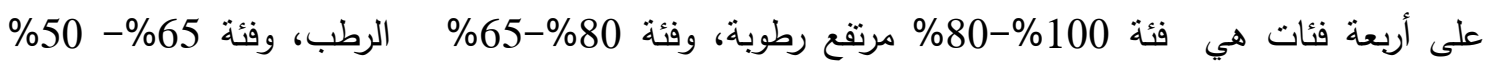
المتوسط الرطوبة، وفئة منخفض الرطوبة أقل من 50\%، ونم تطبيق هذا التصنيف على البيانات الساعية للرطوبة

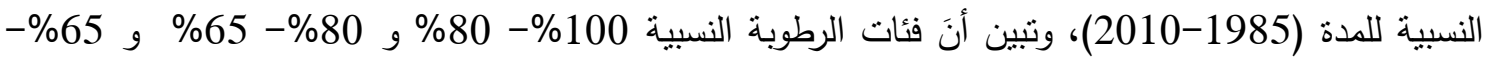

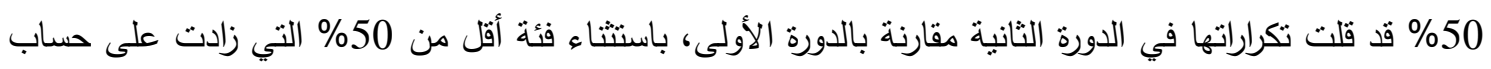

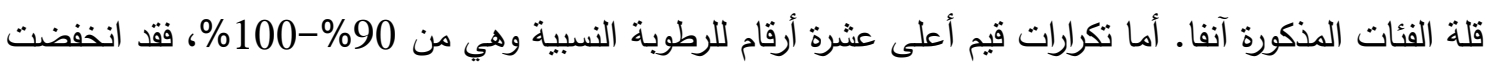
تكراراتها أيضا في الدورة الثانية مقارنة بالدورة الأولى، وسجلت نسبة 96\% ألثرة أعلى فلى فرق فية في التكرارات بين الدورتين.

كما تبينَ أنَ هنالك تغيرات فصلية لتكرار فئات الرطوبة النسبية ما بين الدورتين، ولتحديد أسباب تغير تكرار

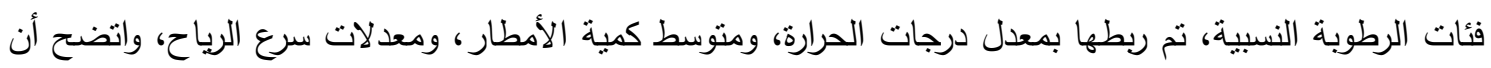

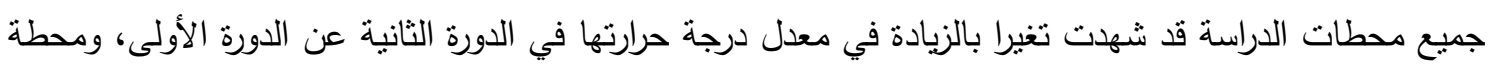

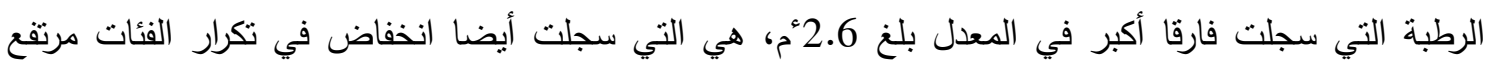
الرطوبة والرطب ومنوسط الرطوبة. ومنوسط الأمطار انخفض بنحو كبير في الدورة الثانية، ومعدلات سرع الرياح

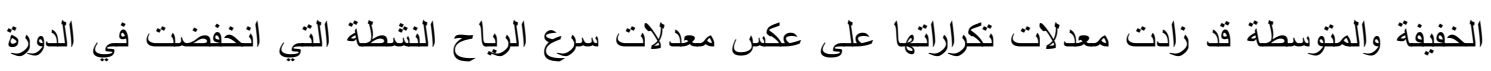
الثانية، يضاف إليها عوامل بيئية أخرى أدت إلى انخفاض قيم الرطوبة النسبية. الكلمات المفتاحية: الرطوبة النسبية، الفئات، درجة الحرارة، الأمطار.

المقدمة:

على الرغم من تعدد طرائق التعبير عن الرطوبة في الجو، إلا أنَ الرطوبة النسبية (R.H) هي أكثرها شيوعا واستخداما، وتعدُ الرطوبة النسبية أحد أبرز عناصر المناخ، لأنها المسؤولة عن معظم عمليات التكاثق من أمطار وزخات مطرية ورذاذ....وسواها بحيث تؤثز في الحياة النباتية، إذ إنَ زيادتها في الجو يؤثرفي عمليات النوازن المائي في داخل أنسجة النبات. ـ والرطوبة النسبية مسؤولة عن مدى شعور الإنسان بالراحة، إذ تم اعتمادها من العالم ثوم(Thom) وأوليفر (Oliver) في وضع صيغ معادلات قياس راحة الجسم (1).

وتتحدد الرطوبة النسبية في الجو بمجموعة من العوامل منها الموقع الجغرافي من خلال القرب والبعد عن المسطحات المائية، ودرجة الحرارة والرياح، والضغط الجويي، وضغط بخار الماء 
في الجو (2)، ويعبر عن درجة تنبع الهواء ببخار الماء عندما نساوي الرطوبة النسبية 100\% بنقة الندى Dewpoint. والملاحظ أنَ نقطة الندى والرطوبة النسبية للهواء تنتاسب طرديا، حيث آني

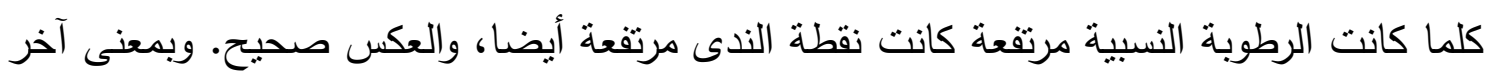
أنَ الهواء الذي يحتوي على نسبة قليلة من الرطوبة يجب أن تتخفض درجة النه حرارته كثيرا، لكي تبدأ

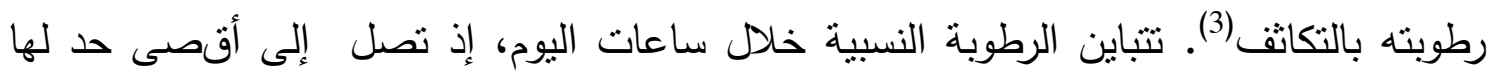

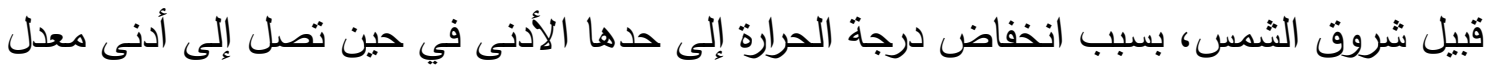

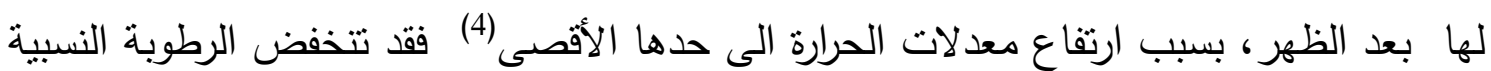

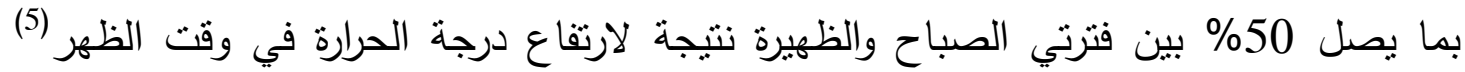
كما تسجل درجات الحرارة المنخفضة جدا خلال فصل الثتاء، بفضل انخفاض الرطوبة النسبية التي نرافقها. أما خلال فصل الصيف فجفاف الهواء يساعد على تسجيل درجات الحرارة الأكثر تطرفال. ويقل حدوث العواصف الغبارية (Dust storm) في المناطق التي نزداد فيها الرطوبة فئاء النسبية، بسبب سقوط الأمطار وكثافة الغطاء النباتيَ، وهذا ما نجده في الأقسام الثمالية من العراق. في حين يزداد حدوثها جنوب دائرة العرض 35 شمالا، بسبب قلة الأمطار، وانعدام الغطاء النباتي واستواء الأرض الجافة (7). ولأهمية الرطوبة النسبية فلم نستنىى من دراسات الباحثين، فدراسة الأسدي(8) التي أستخدم فيها طرق التثثيل الكارتوكرافي (خطوط التساوي) لدورثين مناخيتين أظهرت بأن هنالك تغيرا واضحا في توزيع الرطوبة النسبية، فقد أختقى خط نساوبي

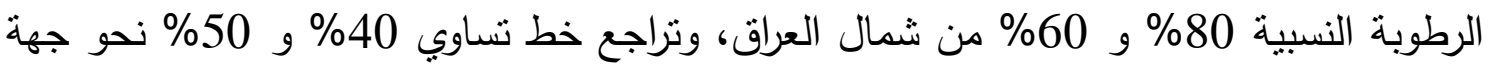
الثمال والثمال الثرقيَ، وظهور خط 30\% في غرب وجنوب غرب العراق، وإنَ أختفاء العديد من لند خطوط تساوي الرطوبة يدل على أنَ مناخ العراق شهد تحول نحو مرحلة أكثر جفافا. أما دراسة الجبور (9) فقد أنشار أنَ الرطوبة النسبية تتغير بطرقتنين، الأولى: بواسطة التبخر والأخرى بواسطة تغير درجة الحرارة، وقد أعتمد على الطريقة الثانية في تفسير تذبذب الرطوبة لمحطتين بغداد والموصل، وبيان اتجاهاتها لتحليل المعدلات السنوية للرطوبة النسبية، وما يقابلها من معدلات درجات الحرارة العظى والاعتيادية والصغرى.

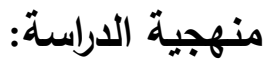

اختيرت المدة (1985-2010) وبالاعتماد على البيانات الساعية للرطوبة النسبية للمحطات موصل كركوك بغداد رطبة بصرة كما في الخريطة (1). وتم تقسيم الدراسة على دورتين مناخيتين،

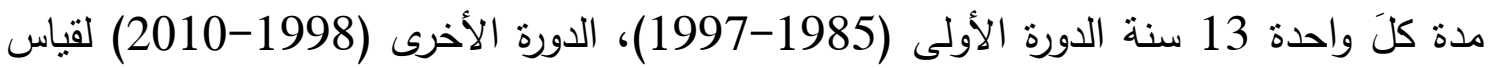
التغيرات في قيم الرطوبة النسبية. 
تعددت تصانيف الرطوبة النسبية، فالبعض بعد الهواء جافا إذا كانت نسبة الرطوبة أقل من

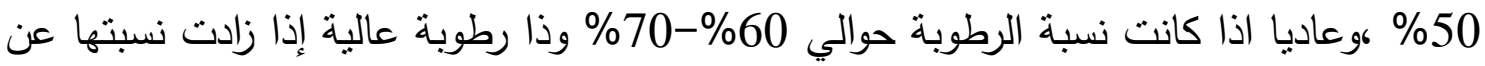

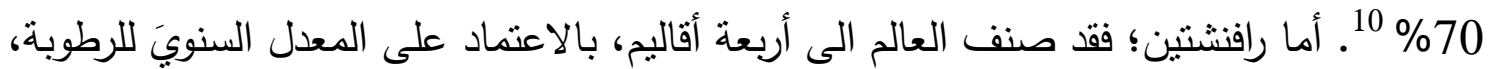

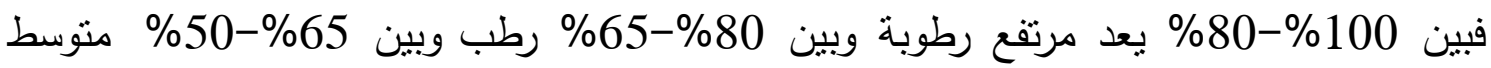
الرطوبة. وأقل من 50\% منخفض الرطوبة(11). ولقياس التغيرات في الرطوبة النسبية العظمى رطي وبن وبن والصغرى سنقوم باعتماد تصنيف رافنشتنين وتطبيقه على البيانات الساعية للرطوبة النسبية.

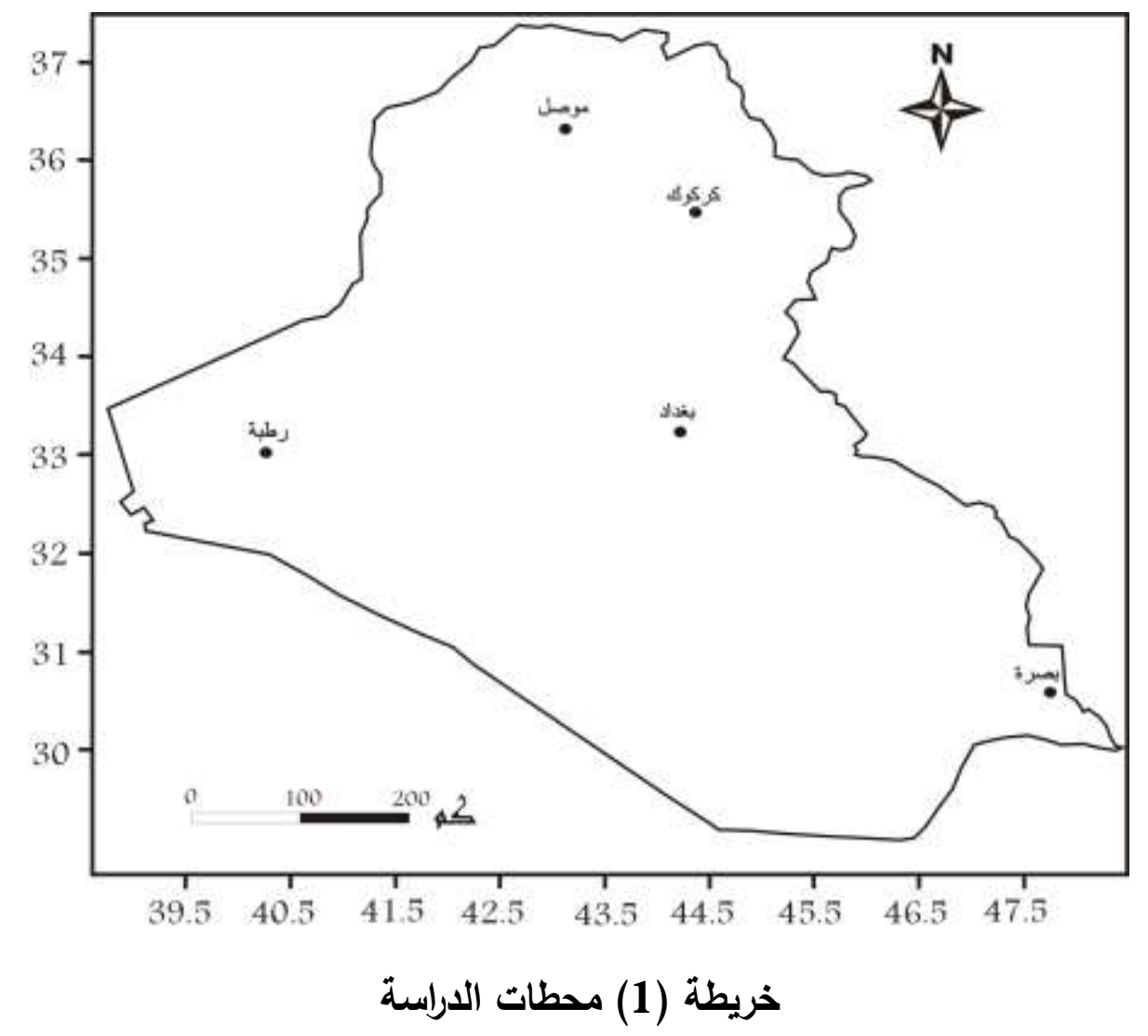

المصدر. أطلس مناخ ألعراق الهيئة العامة للأنواء الجوية والرصد الزيزالي، قسم المناخ (بلان التانة

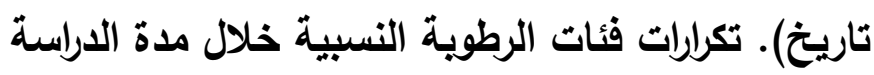

يتضح من الثكل (1) أنَ هناك تباينا واضحا في تكرارات قيم الرطوبة التي تنزاوح بين

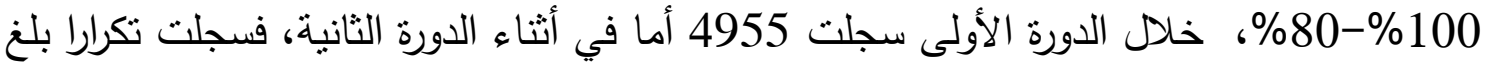

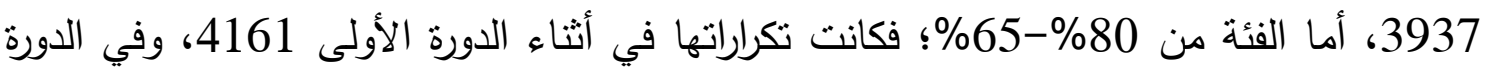

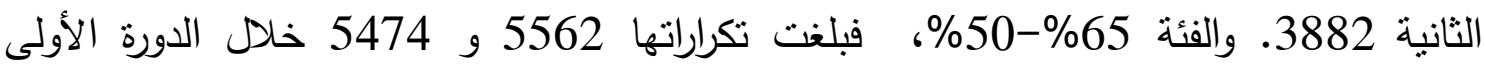

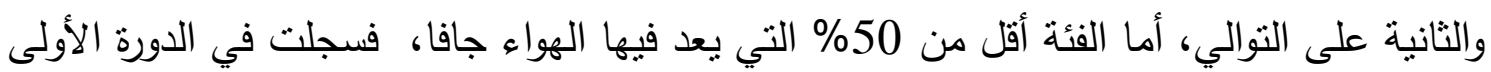
تكرارا، بلغ 23617 وفي الدورة الثانية 25375. 


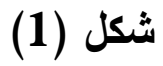

تكرار فئات الرطوبة النسبية خلا الدورتين

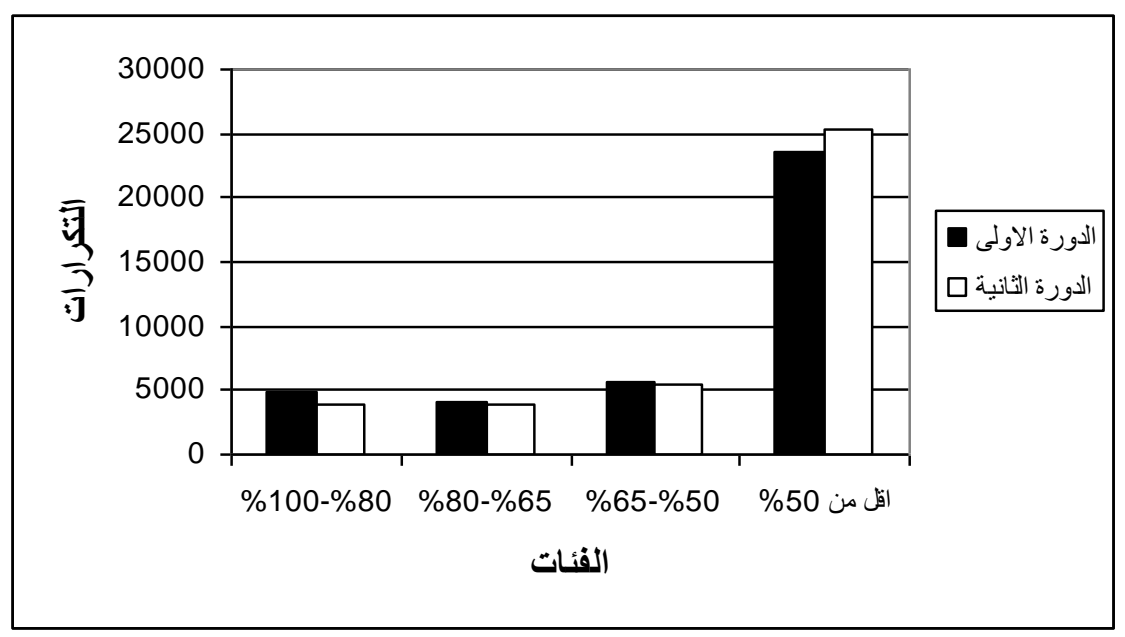

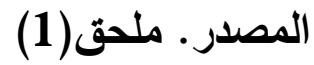

يتضح ممَا سبق أن فئة مرتفع الرطوبة والرطب ومنتوسط الرطوبة قد قلت جميعها خلال

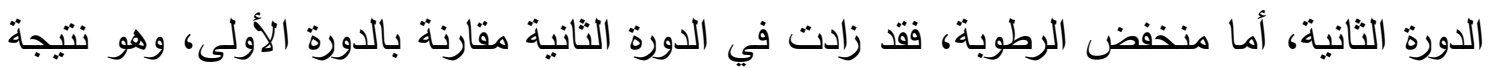
طبيعية، فقلة تسجيل فئة مرتفع الرطوبة والرطب ومنوسط الرطوبة معناه زيادة في تسجيل فئة الرّا منخفض الرطوبة.

كما أنَ ارتفاع درجات الحرارة في السنوات الأخيرة بفعل ظاهرة الاحتباس الحراريَ أدى إلى قلة

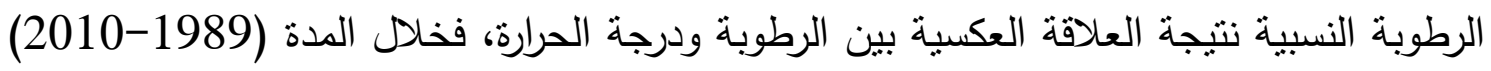

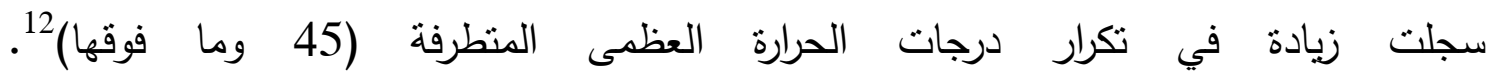

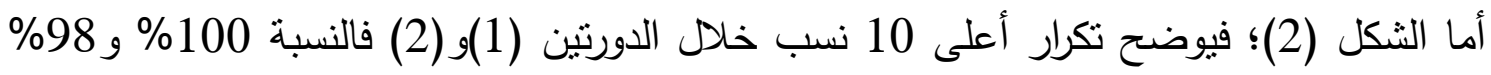
و96\% و95\% 94\% و93\% و92\% و 91\% و 90\% قلت تكراراتها في الدورة الثانية مقارنة

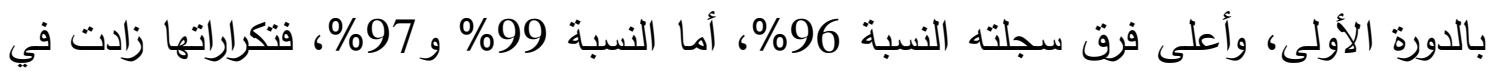
الدورة الثانية مقارنة بالدورة الأولى، لكن هذه الزيادة قليلة> 


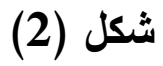

تكرار نسب الرطوبة من 90\%-100\% خلال الدورتين

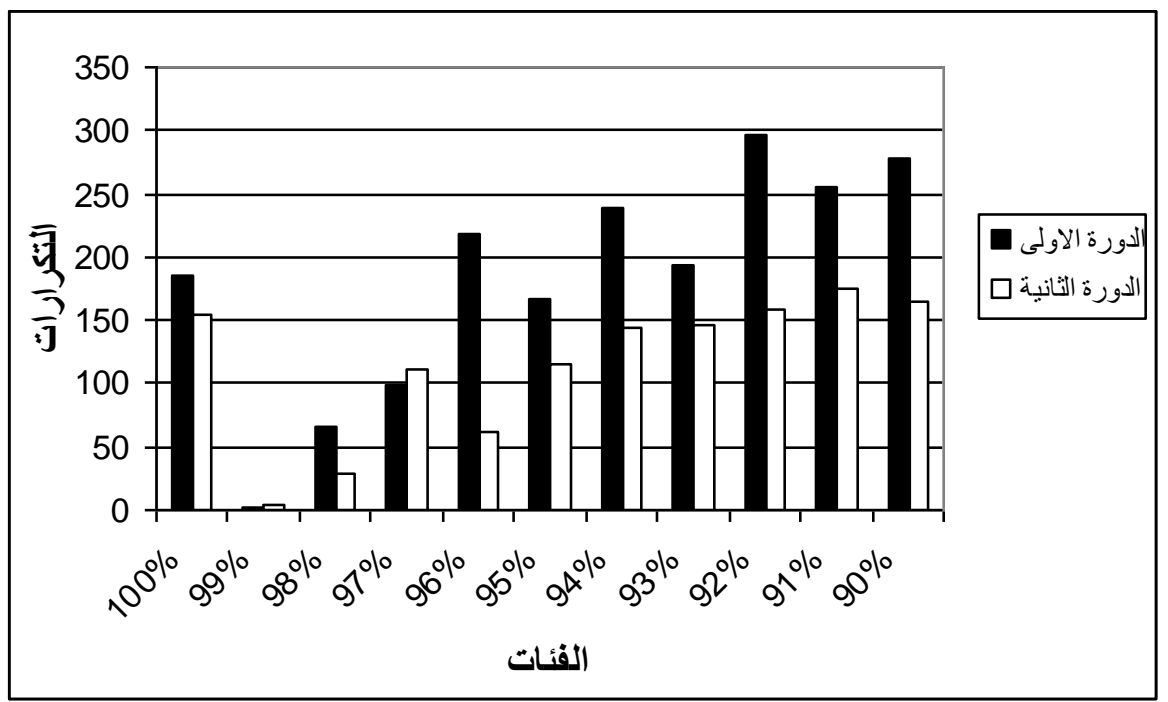

(المصدر . ملحق(2) - (2) - (2)

النسب المئوية لتكرار الفئات:

إنَ النسب المئوية لجميع الفئات تباينت مابين الدورة الأولى والثانية. كما موضح بالثكل (3)، إذ كانت النسب مرتفعة للفئات مرتفع الرطوبة والرطب ومتوسط الرطوبة في الدورة الأولى، وانخفضت باتِ

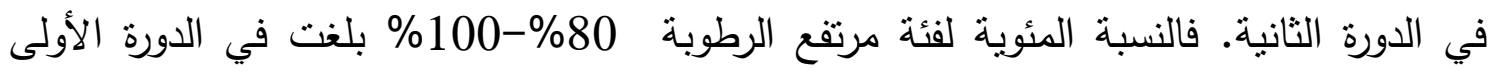
55.7، وانخفضت إلى 44.2\% في الدورة الثانية، وهي الفئة التي سجلت أكبر فرق بين

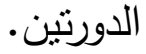

أما فئة الرطب 80\%-65\%؛ ففي الدورة الأولى كانت نسبة تكراراتها 51.7\% ؛ وانخفضت الى 48.2\%، وفئة متوسط الرطوبة 65\%-50\% سجلت نسبة بمقار 50.3\% في

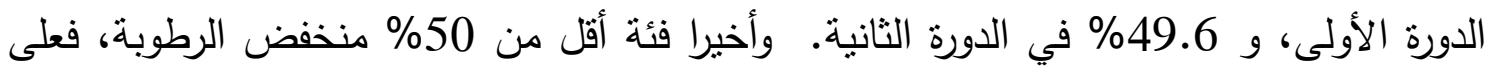

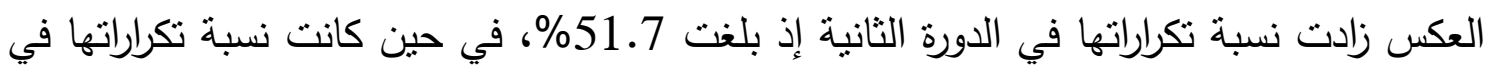

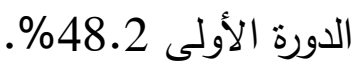




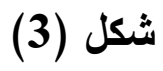

نسبة تكرار الفئات خلال الدورتين

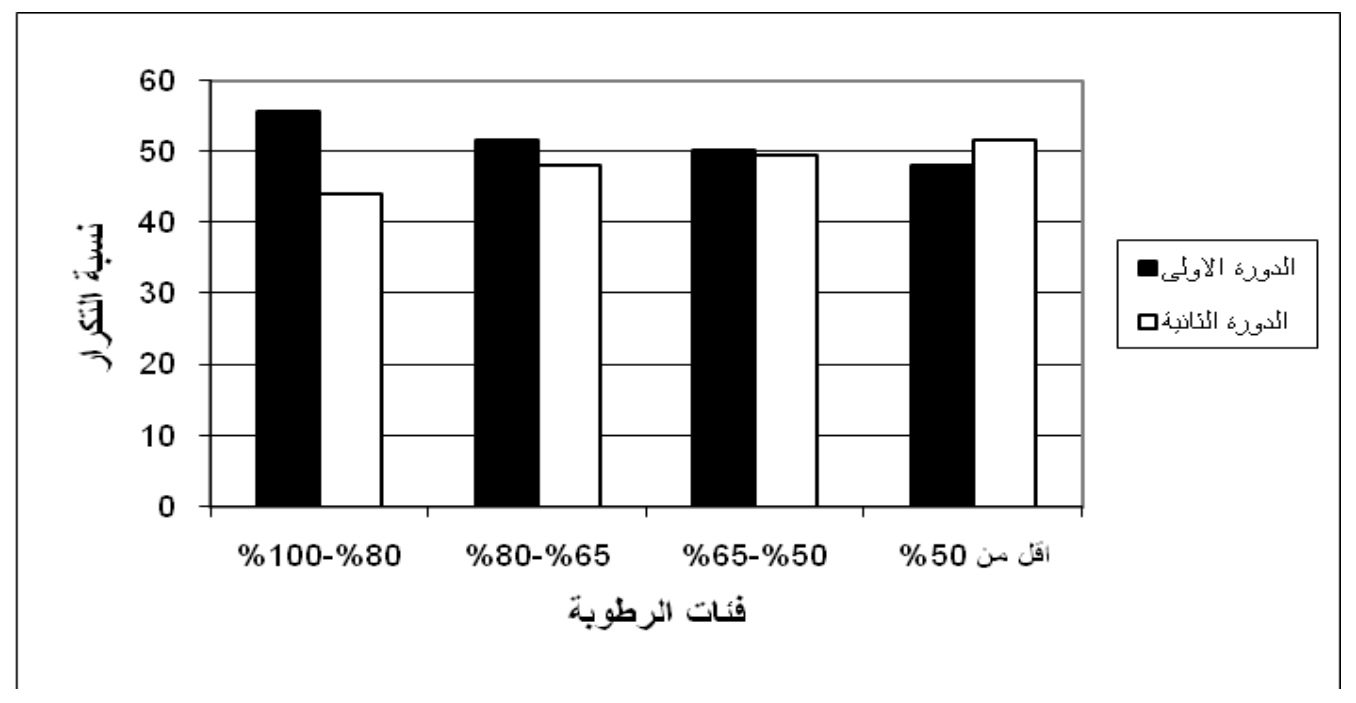

المصدر . ملحق (3)

التغيرات الفصلية لفئات الرطوية النسبية:

يظهر من الثكل (4) أنَ الفئة 100\%-80\% المرتفع الرطوبة تكراراتها قلت بنحو كبير في

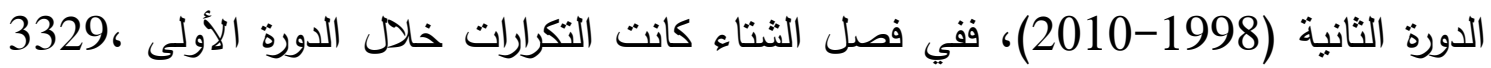
لتصبح في الدورة الثانية 2684. وخلال فصل الربيع سجلت تكرارا خلال الدورة الأولى 1077

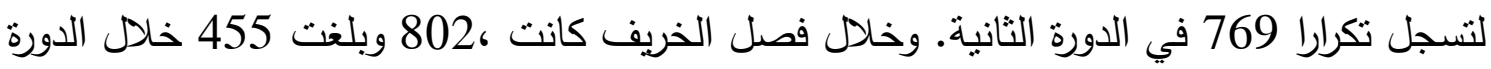

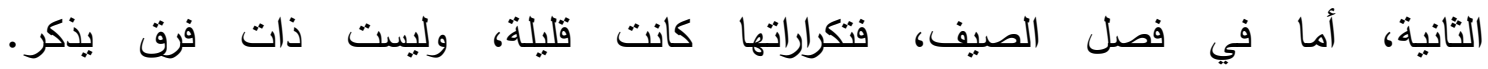

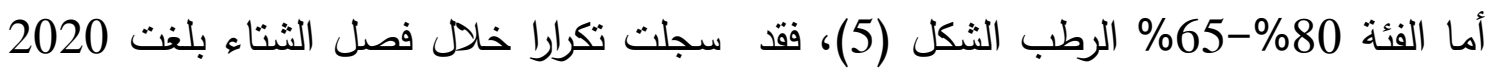
في الدورة الأولى. وفي الدورة الثانية بلغت تكراراتها 2055، نجد أنَها ازدادت في الدورة الثانية

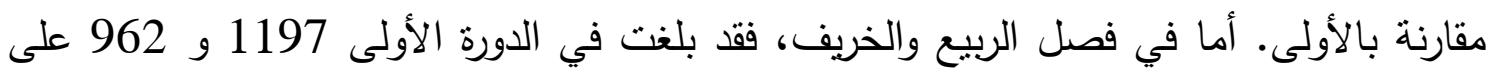
التوالي، لتصبح في الدورة الثانية 1003 و 812. وفصل التصل الصيف سجلت زيادة في التكرار في الدورة الثانية 131، في حين كانت في الدورة الأولى 32. 


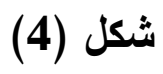

التكرارات الفصلية لفئة المرتفع الرطوبة خلال الدورتين

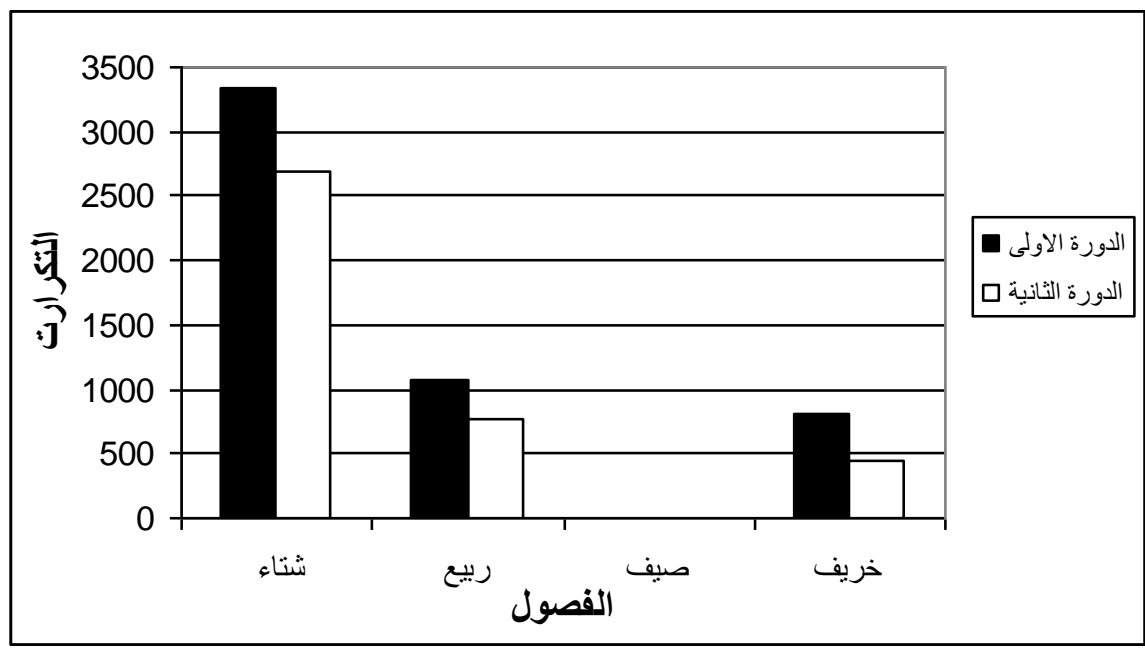

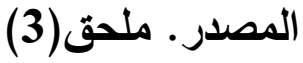

شكل (5)

التكرارات الفصلية لفئة الرطب خلال الدورتين

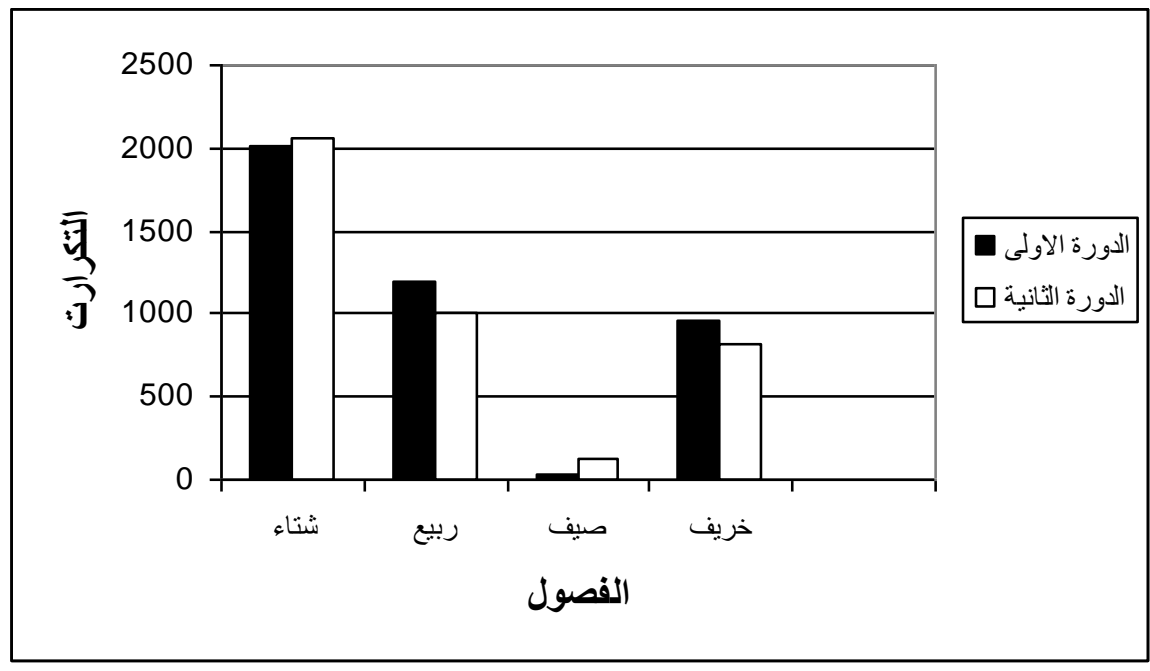

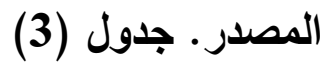

وبالنسبة لفئة متوسط الرطوبة 65\%-50\% الثكل (6)، فالتكرارات خلال الدورة الثانية

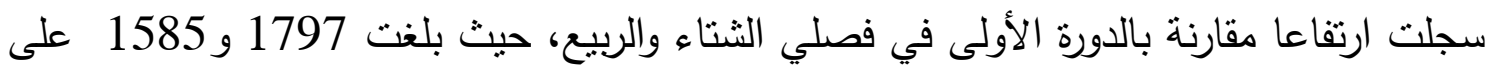
النوالي. في حين كانت تكراراتها 1794-1553 في الدورة الأولى. وفيما يخصة تكرة تكراراتها خلال 
فصل الصيف انخفضت في الدورة الثانية، وفي الخريف فقد قلت في الدورة الأولى مقارنة بالدورة

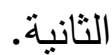

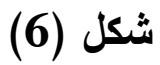

التكرارات الفصلية لفئة متوسط الرطوبة خلال الدورتين

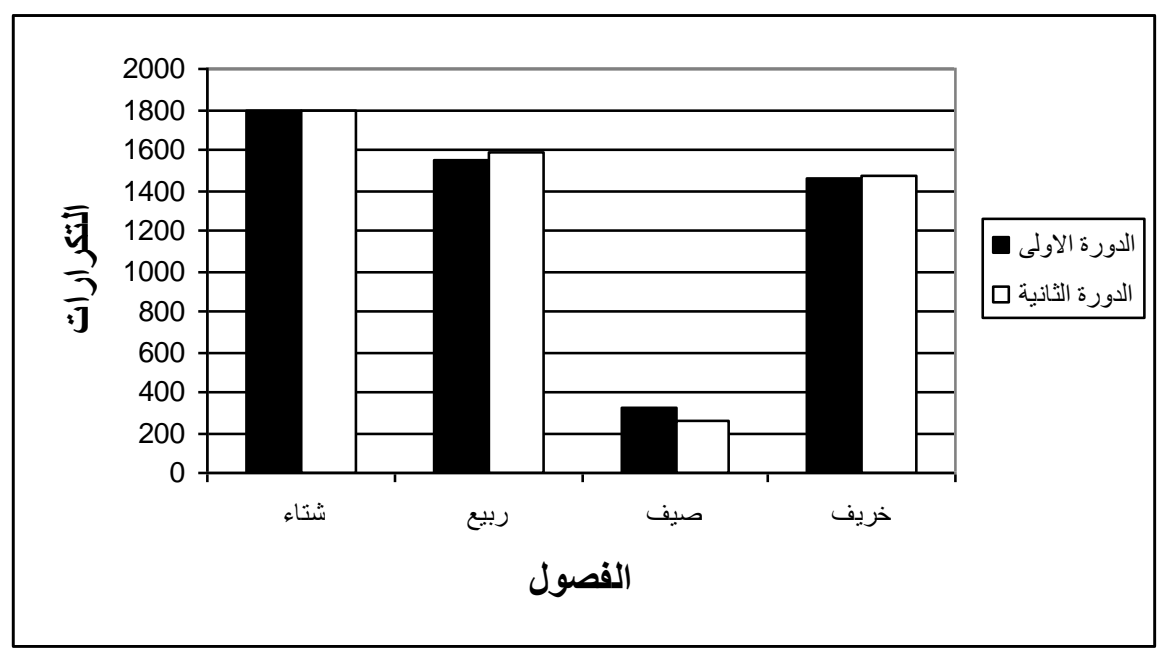

(3) المصدر . ملحق (3)

أما فئة منخفض الرطوبة أقل من 50\%، فقد زادت تكراراتها في الدورة الثانية مقارنة بالدورة الأولى ولجميع الفصول باستثناء فصل الصيف، ففي فصل الثتاء في الدورة الأولى سجلت تكرارا

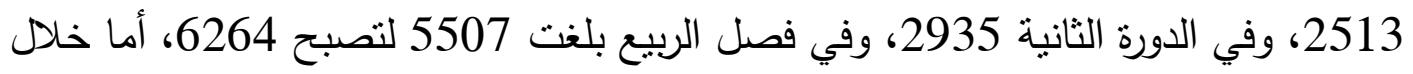

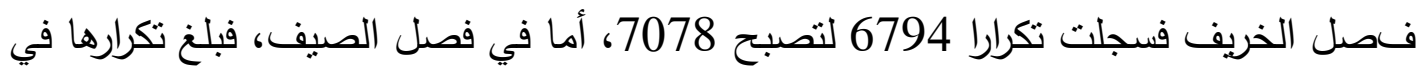

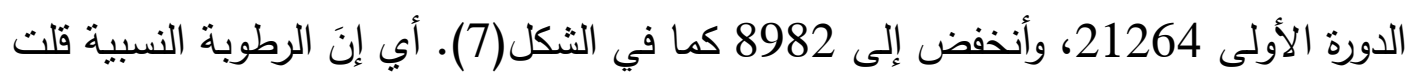
خلال فصل الصيف في السنوات الأخيرة، ليصبح مناخ العراق أثندَ جفافا. 


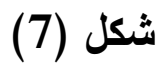

التكرارات الفصلية لفئة منخفض الرطوبة خلال الدورتين

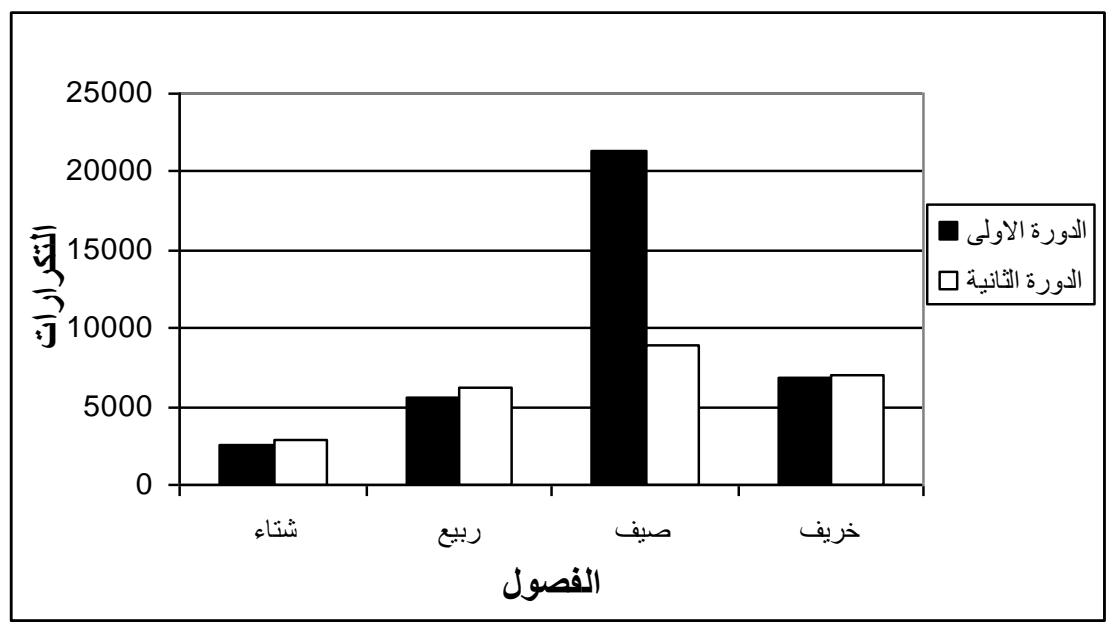

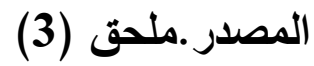

ولتفسير أسباب تغير تكرار فئات الرطوبة خلال مدة الدراسة تم ربطها بمعدل درجات الحرارة

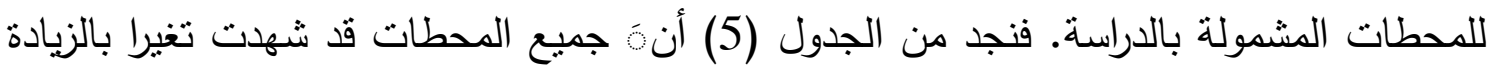

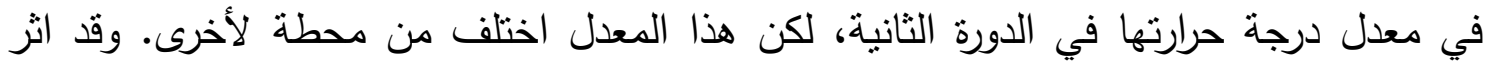

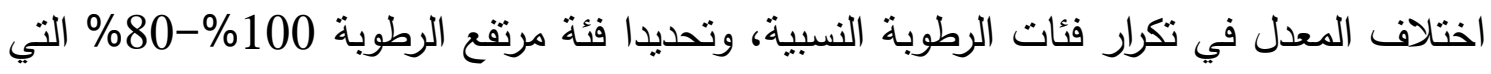
انخفض تكرارها لجميع المحطات في الدورة الثانية. فحطة الموصل سجلت فارقا في معدل درجة

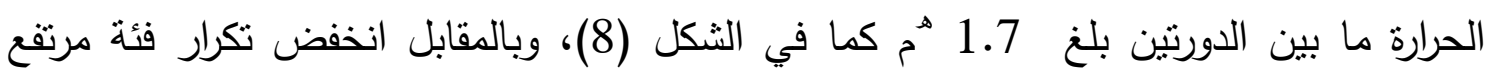

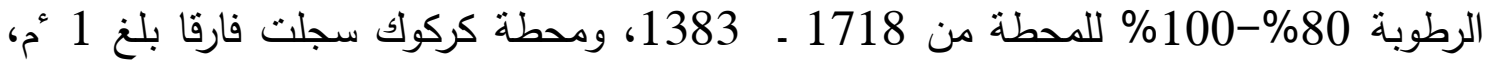
وقد انخفض تكرار فئة مرتفع الرطوبة في الدورة الثانية الى 848، حينما كان 1024ه أما بالنسبة

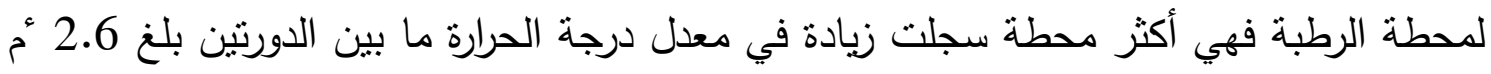

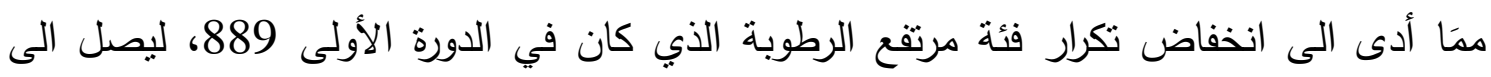

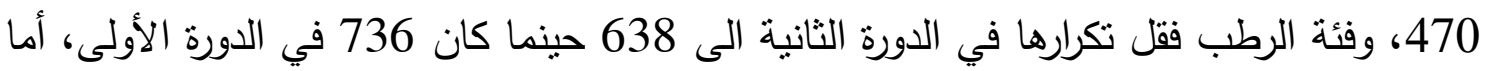

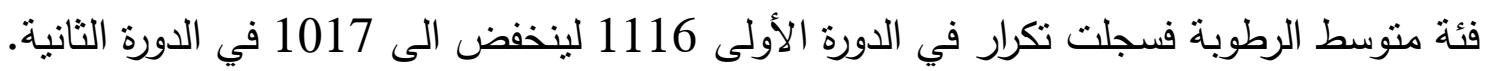
ومحطة بغداد سجلت فرقا بالمعدل بلغ 0.8 هم وبالمقابل أنخفض تكرار فئة المرتفع الرطوبة في

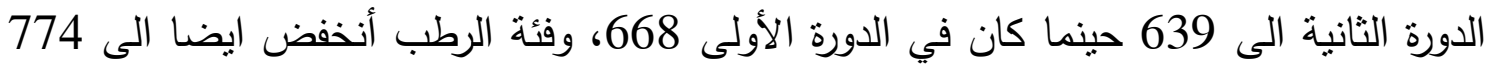

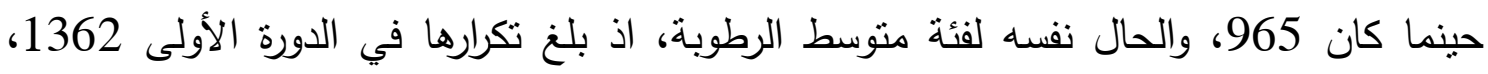

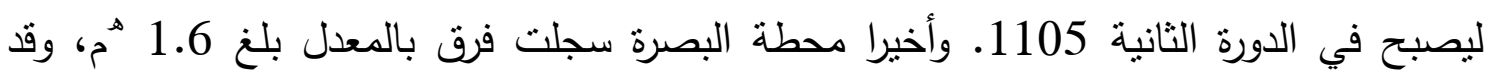


انخفض تكرار الفئة 80\%-100\% في الدورة الثانية الى 597 حينما كان 656 وفئة الرطب التي

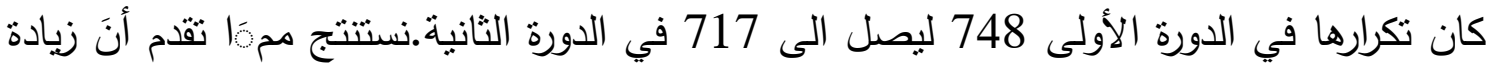
معدلات درجات الحرارة في الدورة الثانية قد أثر بنحو كبير في انخفاض تكرار فئة المرتفع الرطوبة في الدورة الثانية لجميع المحطات ،اما لفئة الرطب فقد انخفض تكرارها لمحطة الرطبة وبغداد

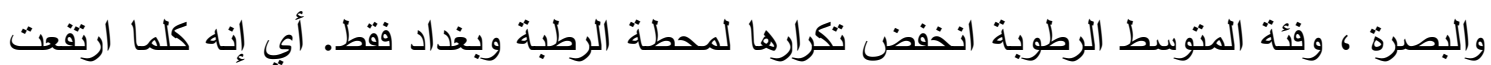
درجة الحرارة أزداد حجم الهواء، فتقل نسبة الرطوبة النسبية فيه.

شكل (8)

\section{الفرق في معدلات درجات الحرارة}

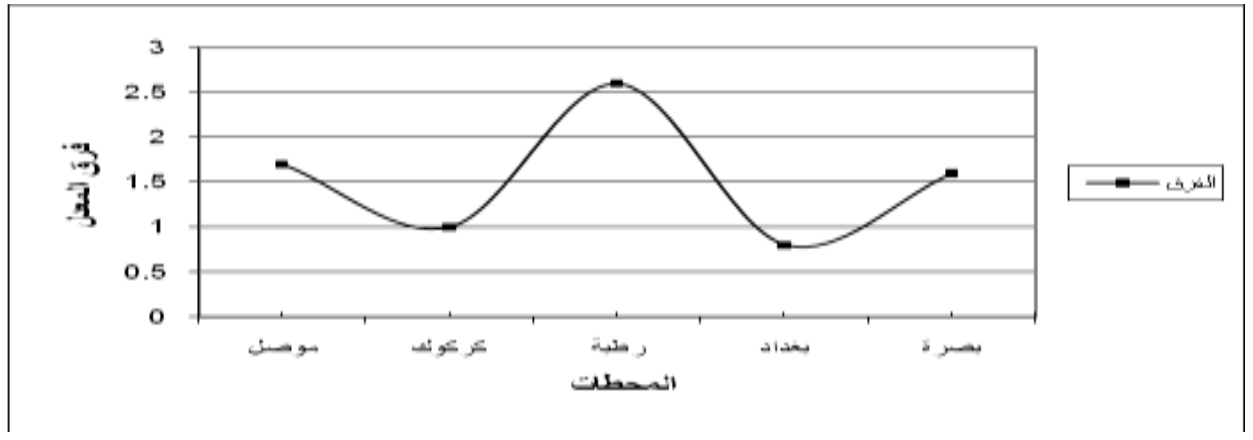

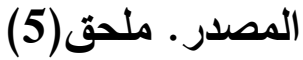

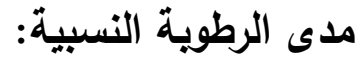

يقصد بمدى الرطوبة النسبية هو الفرق بين متوسط الرطوبة في شهر كانون الثاني الذي يمتل أبرد

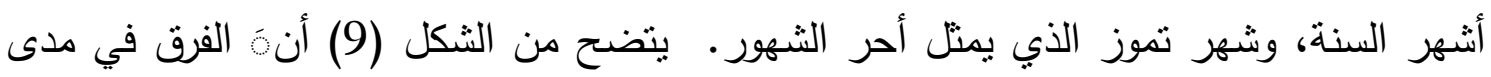
الرطوبة النسبية كان مرتفعا في الدورة الأولى مقارنة بالمدى في الدورة الثانية لجميع الدحطات، باستثاء محطة البصرة التي كان فيها المدى بين الدورتين ليس بفارق كبير . شكل (9) مدى الرطوبة النسبية لمحطات الدراسة خلال الدورتين

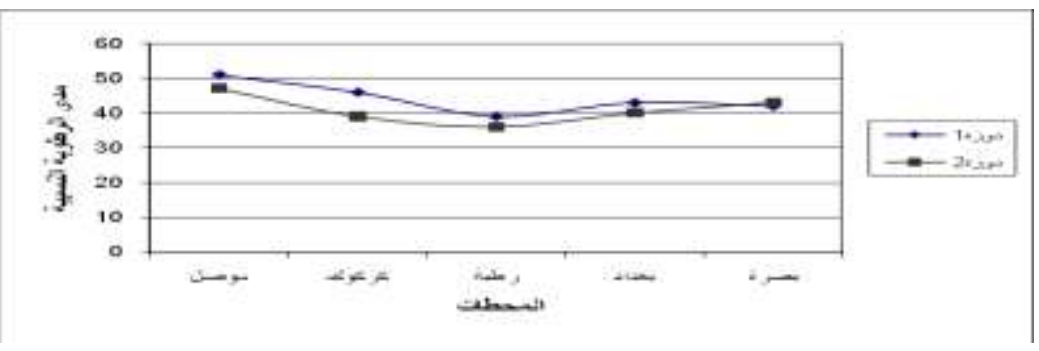

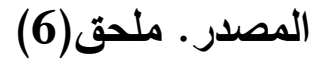


فحطة الموصل كان مدى الرطوبة النسبية 51\%، وانخفض في الدورة الثانية 47\%،

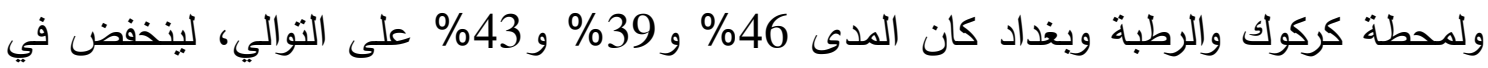

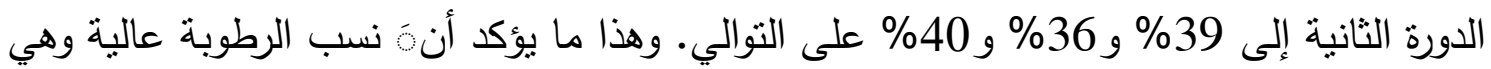

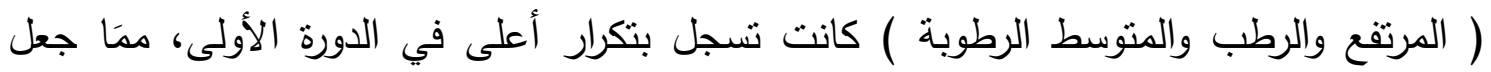

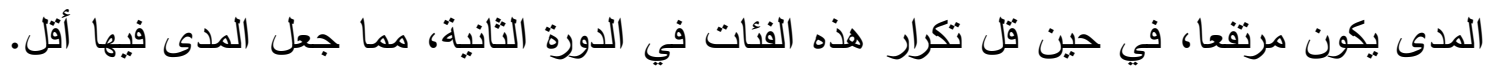

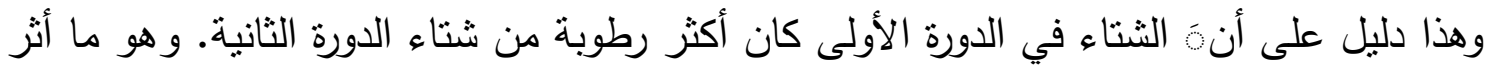

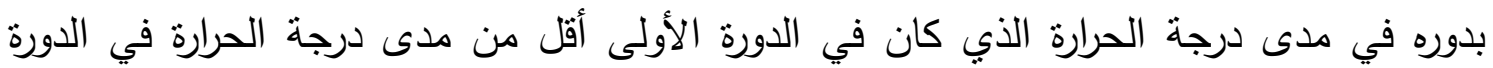

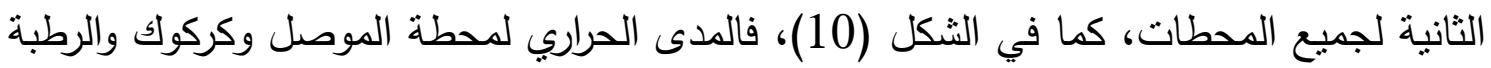
وبغداد وبصرة كان 27.1 و 26.8 و 23.8 و 24.8 و 25.1 على التوالي، وازداد المدى في الدورة الثانية الى 28.3 و 27.2 و 24.8 و 25.9 و 25.8 على التوالي. يتبي وَن مدَا تقدم أنَ العلاقة عكسية بين مدى الرطوبة النسبية ومدى درجة الحرارة، فكلما ارتفع مدى الرطوبة النسبية

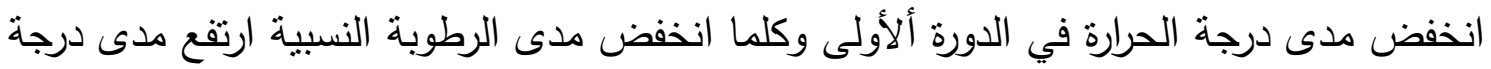
الحرارة، وهذا ما نجده في الدورة الثانية .

شكل (10)الددى الحراري لمحطات الدراسة خلال الدورتين

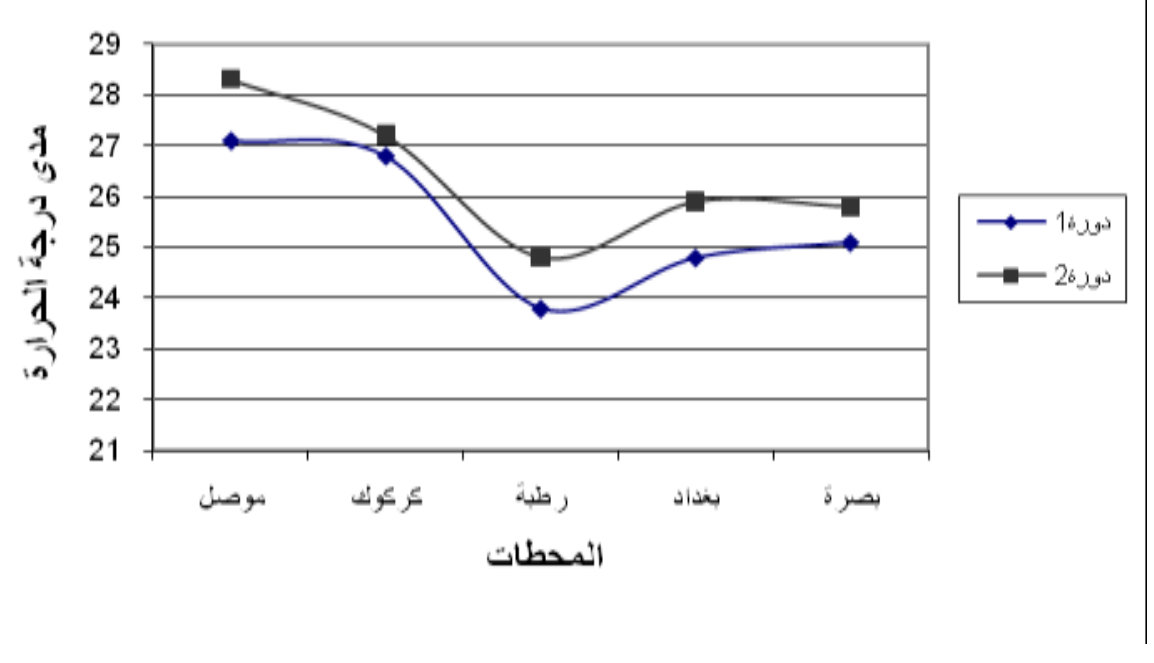

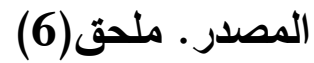

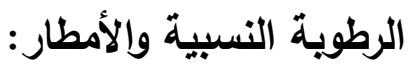

تزداد الرطوبة النسبية بعد تساقط الأمطار، لذلك تم حساب متوسط كمية الأمطار خلال

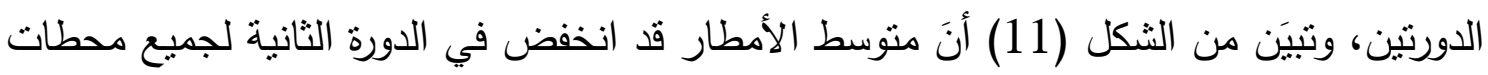
الدراسة بنحو كبير. فلمطة الموصل انخفض المنوسط من 36.1ملم في الدورة الأولى الى مئى 
24.2ملم في الدورة الثانية، ولمحطة كركوك من 35.9ملم الى 22.8ملم، ومحطة الرطبة انخفض المتوسط من 13.5ملم إلى 6.8ملم، ومحطة بغداد من 10.1ملم إلى 7.6ملم، واخيرا محطة

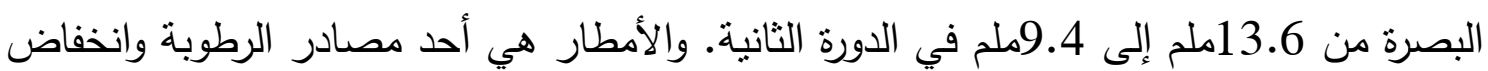

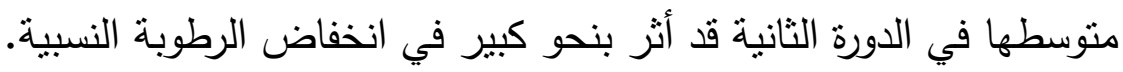
الثنكل(11)

متوسط الامطار بالملم لمحطات الدراسة خلال الدورتين

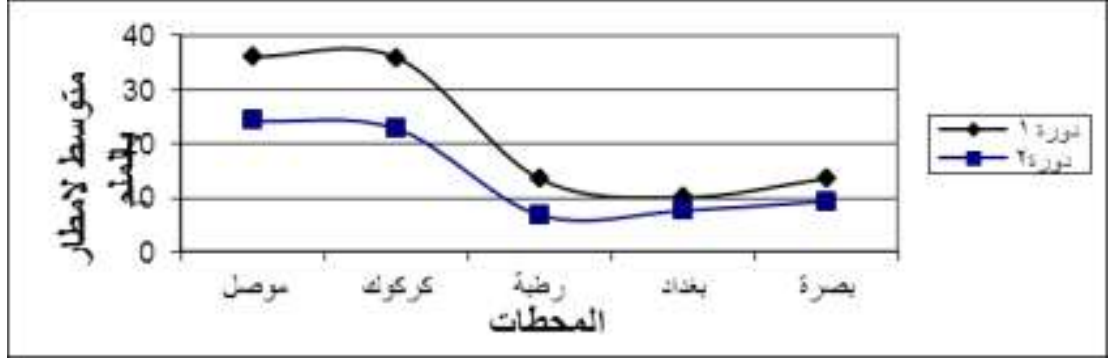

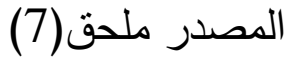

الرطوية النسبية وسرع الرياح:

يعدُ العراق من البلدان التي تتميز بانخفاض معدلات سرع الرياح لوقوعه ضمن نطاق

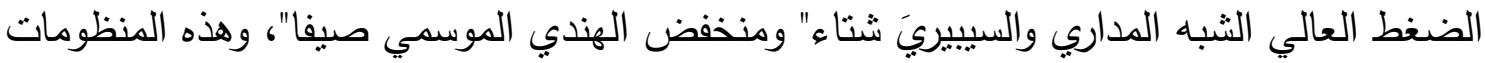
لا تساعد على هبوب رياح سريعة ونشطة باستثاء الحالات الجوية التي تحدث فيها المنخفضات

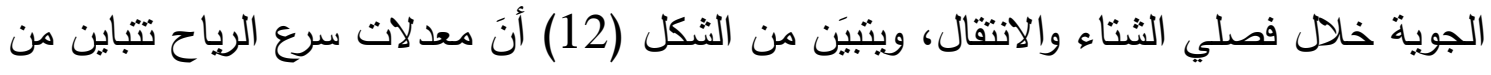

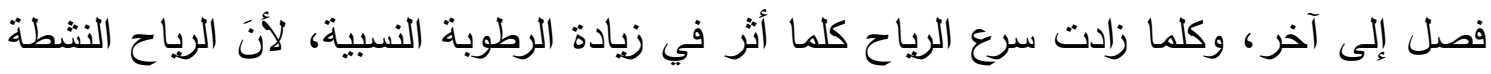

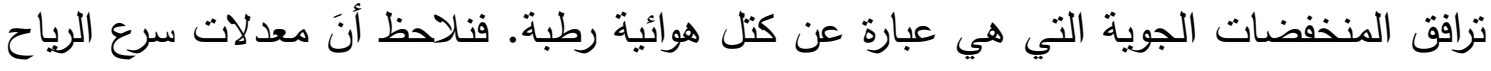

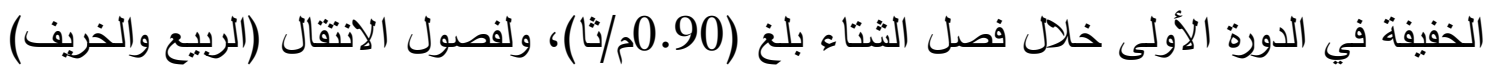

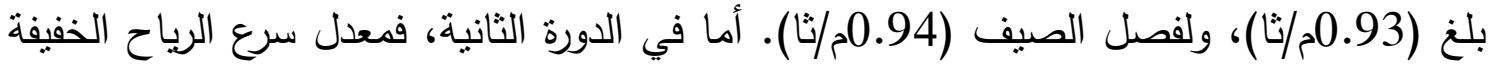

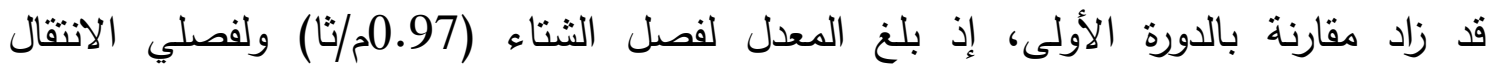
(1.08م/ثا) ولفصل الصيف (23.1م/ثاً) وهذا يدلهُ على أنَ سرع الرياح الخفيفة التي زاد معدل

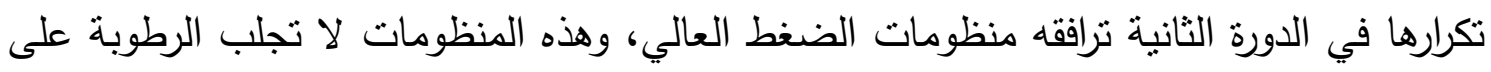

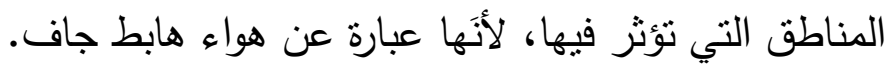

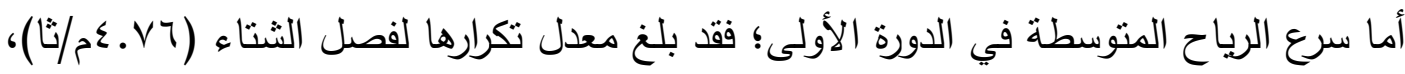

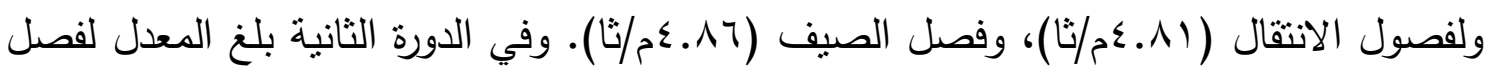

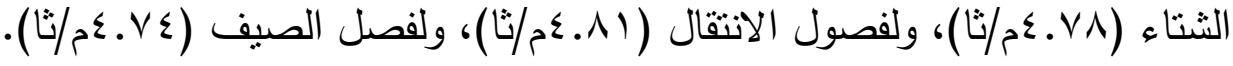


نستتنج من ذلك أنَ معدلات سرع الرياح قد زاد تكرارها خلال فصل الثتاء، ولا يوجد تغيير في

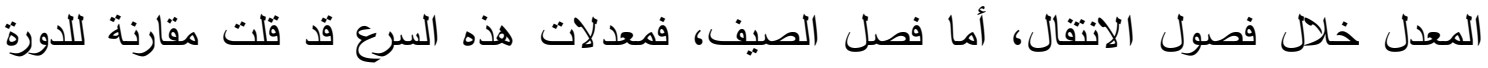
الأولى، وهذا معناه أنَ المرتفعات الجوية تؤثز بنحو كبير في الرطوبة النسبية.

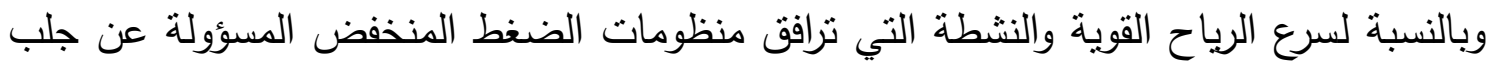

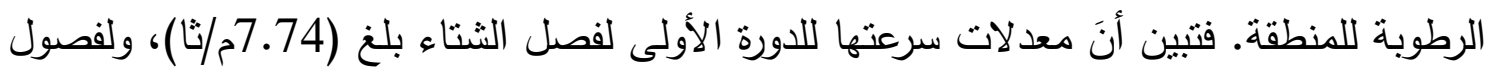

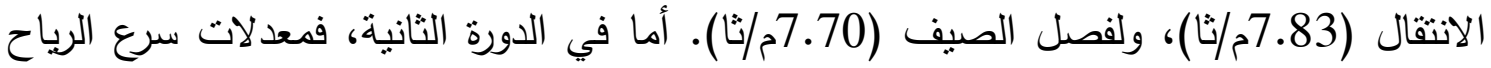

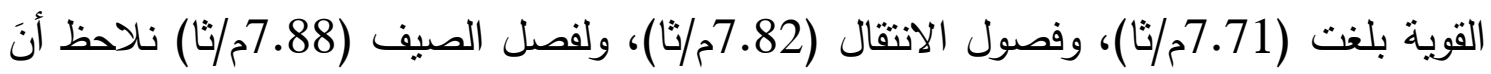

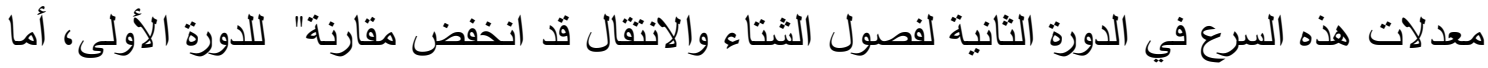

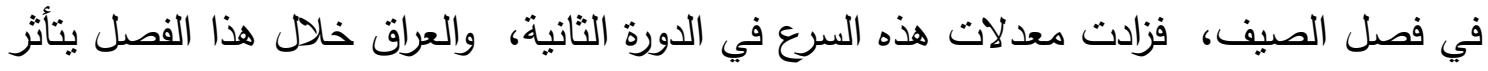
بمنظومة المنخفض الهندي الموسميَ الذي يصل للعراق جافا.

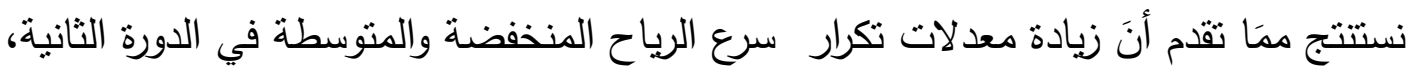
وانخفاض معدلات سرع الرياح النشطة قد انعكس على نسب الرطوبة فئل في الدورة نفسها. شكل (12)

معدلات سرع الرياح م/ثا خلال الدورتين
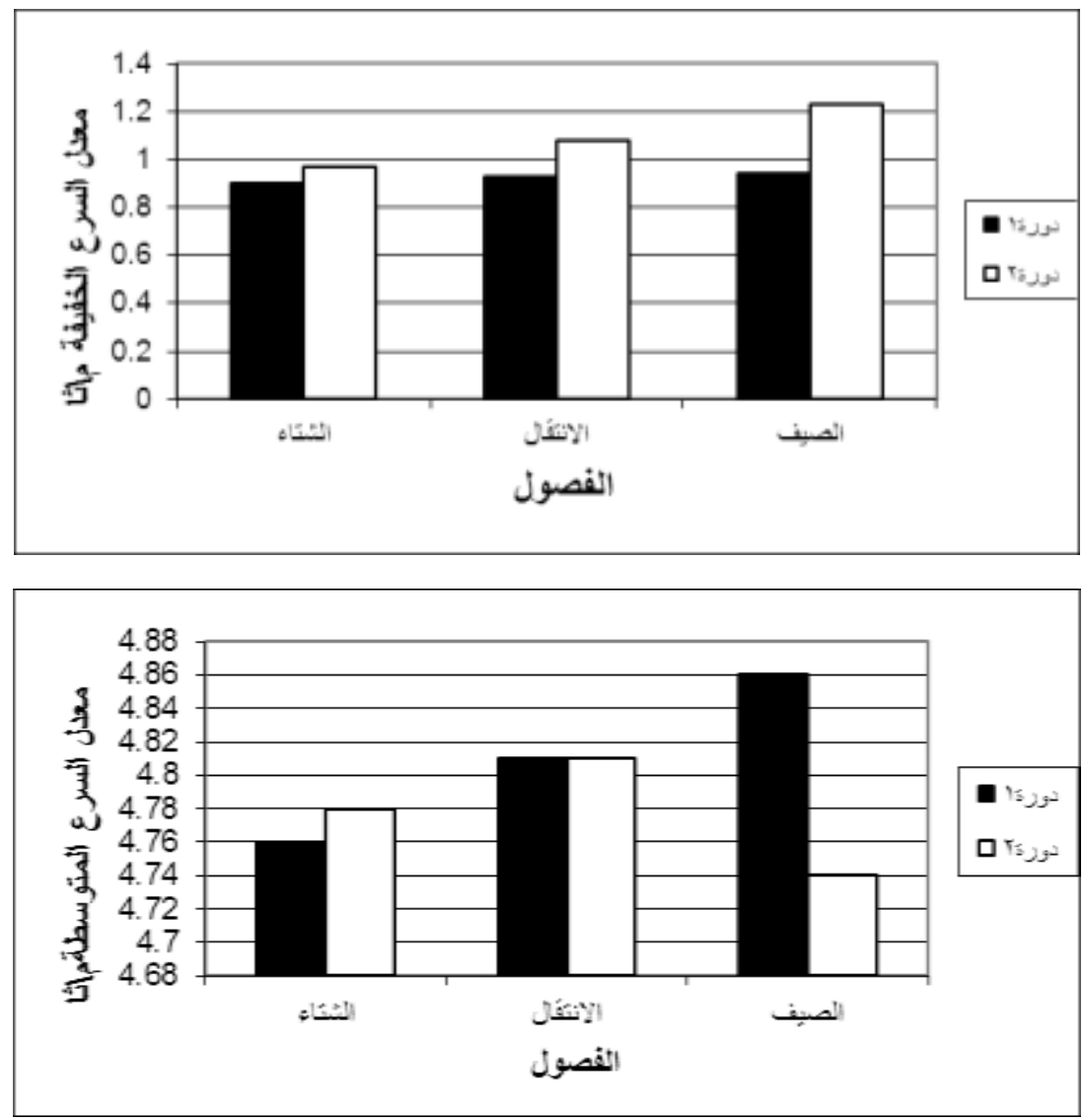


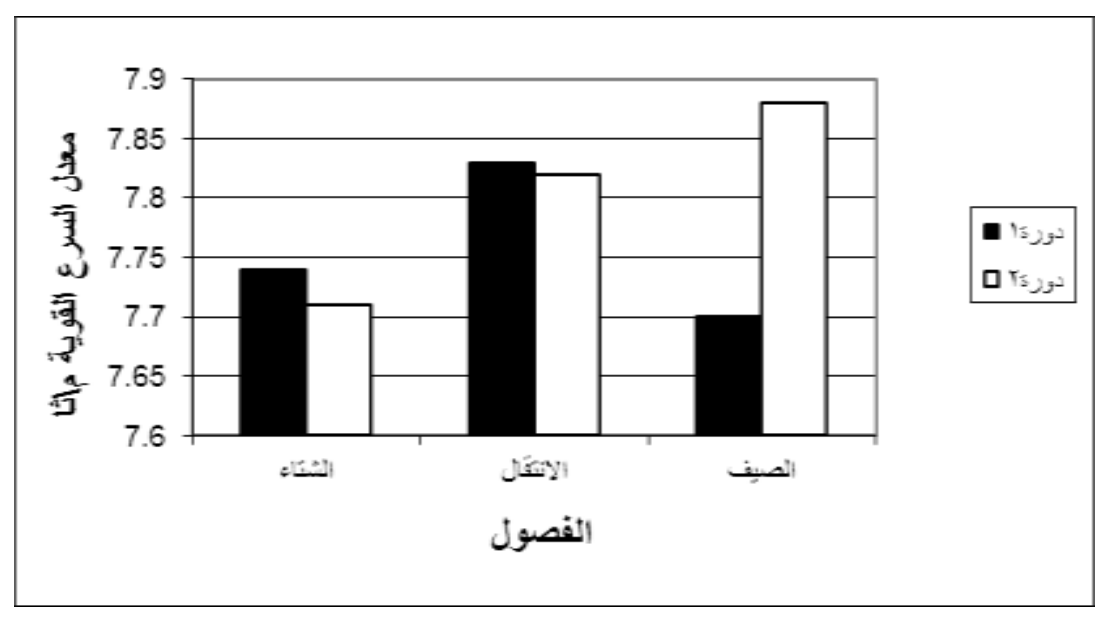

المصدر.ملحق (8)

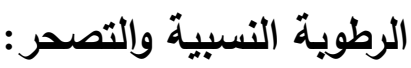

إنَّ اتساع رقعة الأراضي الصحراوية والمتصحرة على حساب الأراضي الزراعية والمراعي

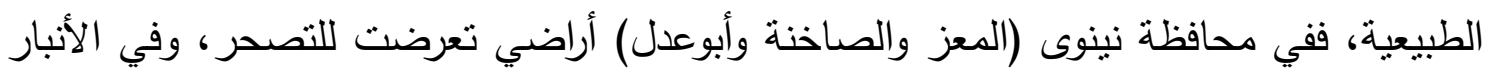

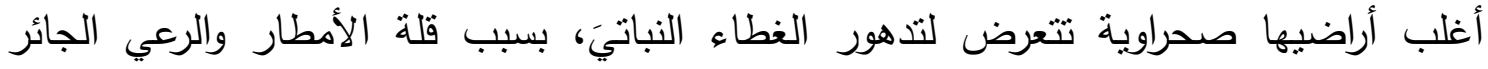

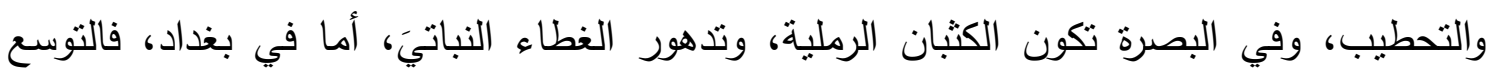

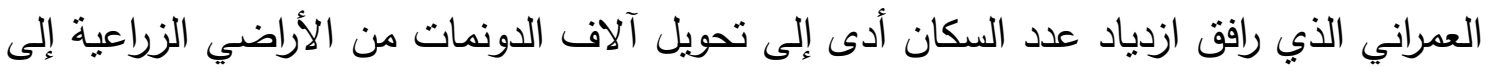

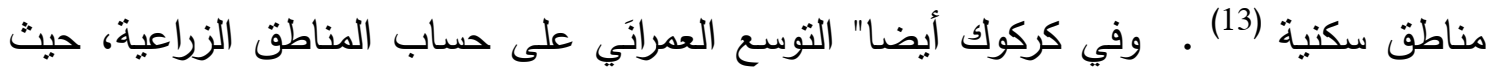

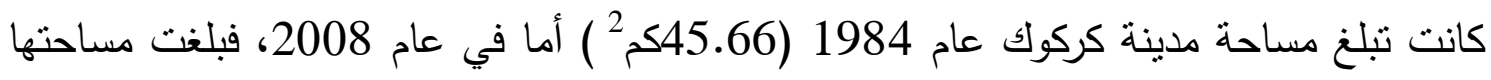
(109.45م² ) حيث إنَ اتساعها كان نحو الغرب والجنوب، أي باتجاه الأراضي السهلية

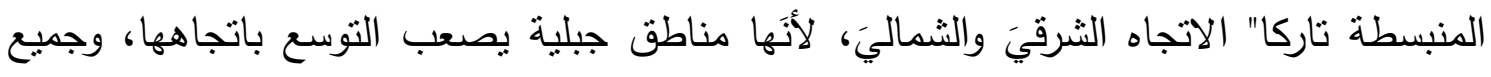

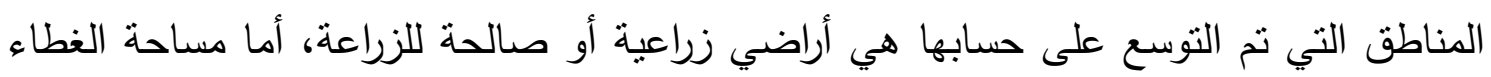
النباتيَ فتتاقصت النسبة من (16.7\% 15000كم² من الأهوار في جنوب العراق أدى الى تغيير الخصائص المناخية للمنطقة، حيث

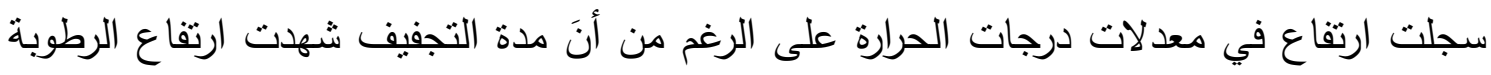

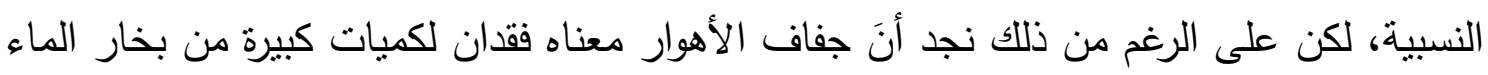

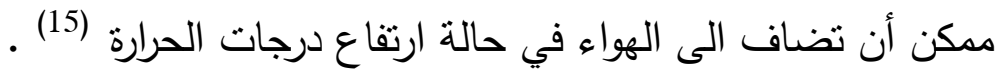

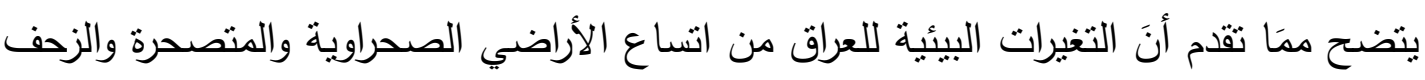

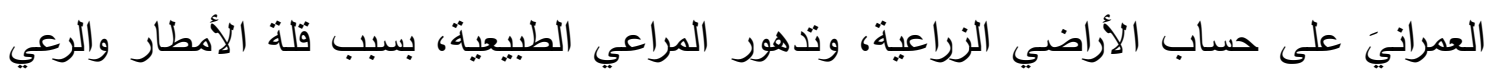

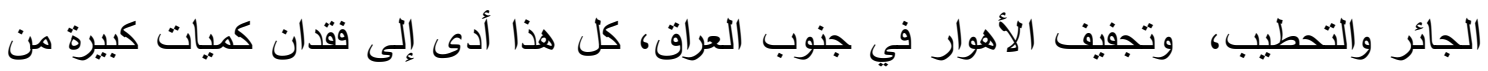


بخار الماء، كان بالإمكان أنَ تضاف إلى الهواء عن طريق التبخر ، مما أثر في معدلات الرطوبة

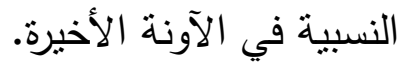

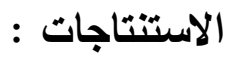
توصل البحث إلى ما يأتي: ا ـ قلت تكرارات فئات الرطوبة النسبية 100\%-80\% مرتفع الرطوبة و 80\%-65\% باني" و65\%-50\% منوسط الرطوبة في الدورة الثانية مقارنة بالدورة الأولى الرطب باستثناء فئة

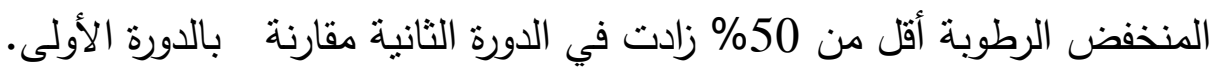

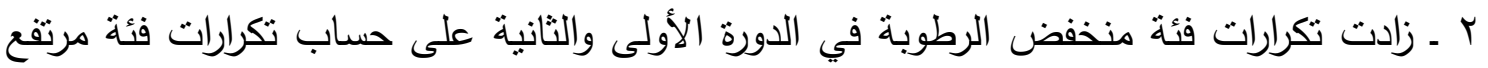
الرطوبة والرطب ومنوسط الرطوبة .

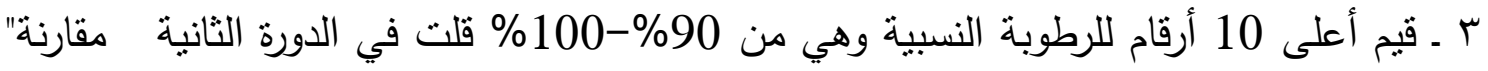

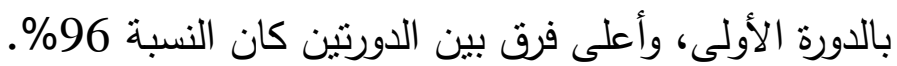
ع ـ فئة مرتفع الرطوبة 100\%-80\% كانت أكثر تكرارا" خلال الدورة الأولى مقارنة" بالدورة الثانية لفصل الثتاء والربيع والخريف.

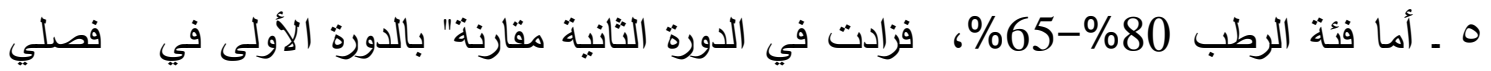
الربيع والصيف، أما في فصلي الثتاء والخريف، فقلت في الدورة الثانية عن الدورة الأولى.

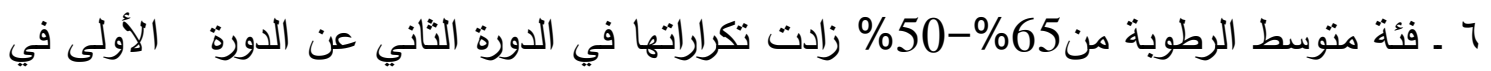
فصل الربيع والخريف والثتاء وقلت في فصل الصيف. V ـ فئة أقل من 50\% منخفض الرطوبة كانت تكراراتها في الدورة الثانية أعلى من الدورة الأولى فئى ولجميع الفصول. ^ ـ سجلت محطة الرطبة أكبر فارق بالزيادة في معدل درجات الحرارة بين الدورتين وهي بذلك

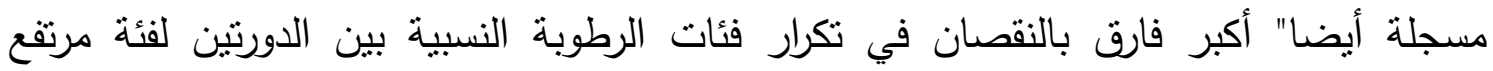
الرطوبة والرطب ومنوسط الرطوبة. 9 ـ إنَ العلاقة عكسية بين مدى الرطوبة النسبية ومدى درجة الحرارة، فكلما أرتفع مدى الرطوبة

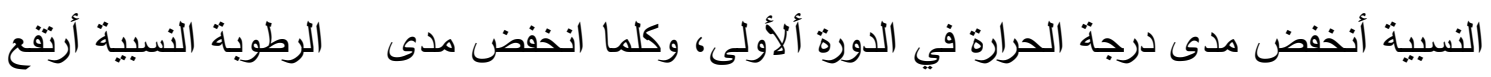
مدى درجة الحرارة، وهذا ما نجده في الدورة الثانية.

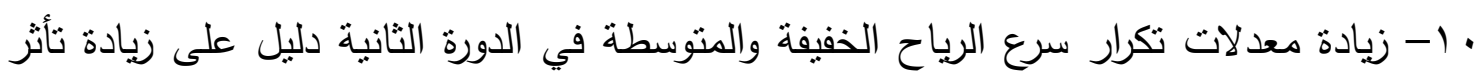

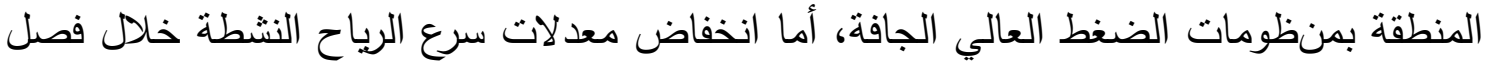
الثتاء والانتقال؛ فدليل على قلة تكرار المنخفضات الجوية الرطبة. 


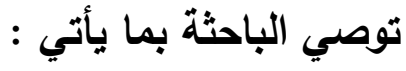

I ـ ـ إجراء دراسة عن تغيرات الرطوبة النسبية وربطها بعناصر مناخية أخرى كالضباب والتبخر . r ـ ـ تحديد المنظومات الضغطية الفصلية المسؤولة عن زيادة الرطوبة النسبية وقلتها في العراق. 
1. علي صاحب الموسوي، وعبد الحسن مدفون أبو رحيل، المناخ التطبيقي، دار الضياء للطباعة، النجف الأثرف،

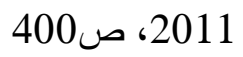

2. علي صاحب الموسوي، وعبد الحسن مدفون أبو رحيل، مناخ العراق، الطبعة الأولى، مطبعة الميزان، النجف الأثترف، 2013، ص182

3. أحمد سعيد حديد و فاضل الحسني، علم المناخ، وزارة التعليم العالي والبحث العلمي، مطبعة جامعة بغداد، 1984 190 ص150 4. صباح الراوي و عدنان البياتي، أسس علم المناخ، وزارة التعليم العالي والبحث العلمي، جامعة الموصل،

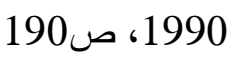

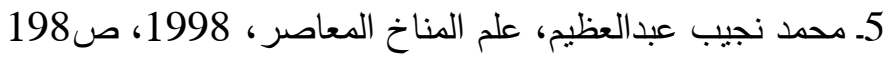
6. عبدالرحمن حميذة، علم المناخ، مطبعة جامعة دمثق، دمثق،

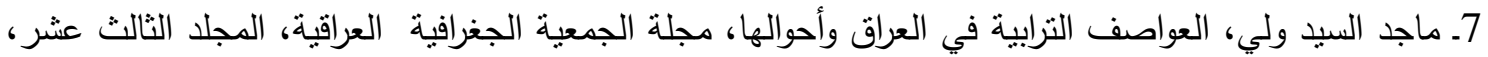

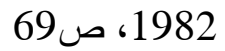
8. كاظم عبدالوهاب الأسدي، أثز التغير المناخي في تغير خطوط تساوي الرطوبة النسبية في العراق، مجلة آداب

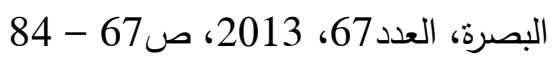
9. سلام هاتق أحمد الجبوري، تذبذب الرطوبة النسبية واتجاهاتها في مدينتي بغداد والموصل للمدة 1982-

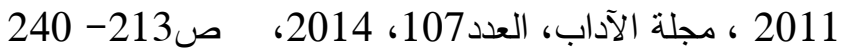
10ـ محمد أحمد النطاح، الأرصاد الجوية، الجزء الأول، الطبعة الأولى، الدار الجماهبرية للنشر والتوزيع والأعلام،

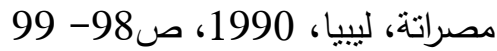
11. قصي عبدالمجيد السامرائي، المناخ والأقاليم المناخية، دار اليازوري العلمية للنشر والتوزيع، عمان، 2008، ص144

12. سالارعلي خضر الدزيي وبشرى أحمد صالح، تحديد مؤثرات التغير المناخي في العراق من خلال تحليل

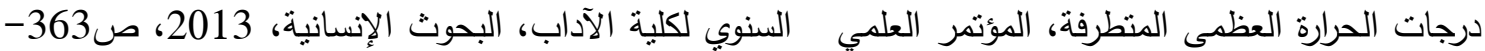
.386

13. نقرير الإحصاءات البيئية لسنة 2006، وزارة التخطيط، بغداد 2007،صرئ51-55 14. نهرين حسن عبود، ظاهرة التصحر في محافظة كركوك، رسالة ماجستير مقدمة الى مجلس كلية التربية للبنات

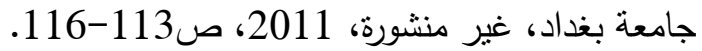
15. يوسف محمد علي الهذال، تجفيف الأهوار وأثره في اختلاف الخصائص المناخية ل لجنوب العراق، مجلة البيئة العراقية الجديدة تصدرها منظمة مكافحة التلوث البيئي والتصدر في العراق، عدد خاص ببحوث المؤتمر

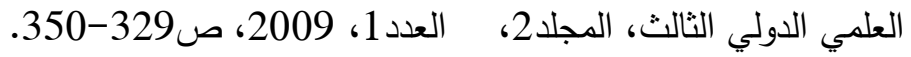




\title{
The Changes in Categories Relative Humidity in Iraq \\ Dr.bushra A.Juad \\ University of Al- Mustansiriya \\ College of Education \\ Dept artment of Geoghraphy \\ D.Bushra Ahmed @yahoo.Com
}

\begin{abstract}
$\underline{\text { Abstract }}$
The aim of this reaserch is study the change in relative humidity(R.H)categories, which is divided according to classification scientist Ravinshteen it is humidity high category $100 \%-80 \%$, humidities $80 \%-65 \%$ humidity medium 65\%-50\%and humidity low category less than 50\%. and applied this classification on the hours data period (1985-2010). It is show the R.H categories $100 \%-80 \%, 80 \%-65 \%$ and $65 \%-50 \%$ recored low frequency in second session comparison first session exception humidity low category which is record high frequency at the expense of other categories.concering frequency value high ten number $100 \%-90 \%$ which is lowest frequency too in the second cycle the value $96 \%$ record hight diffrence in frequency between two cycle. And there are seasonal changes between two session. To determind the reasons of this changes in( R.H) categories its correlation with average temperature and rainfall and rate of wind speed. It has been found all the study station witness change increase in average temperature in the second session comparison first session and Rutba station record high difference in average reach 2.6C.and average of rainfall is also dropped in second session . the average frequency of wind speed, the low and medium speed is increase in second session comparison speed strong wind which dropped in second cycle in addition there are another egology facts result to low value of (R.H)

Key words

Relative Humidity, Categories , Temperature , Rainfall
\end{abstract}

